\title{
The Aesthetics of Zipai: From Wechat Selfies to Self-Representation in Contemporary Chinese Art and Photography
}

GABRIELE DE SETA, The Hong Kong Polytechnic University

MICHELLE PROKSELL, Performance artist \& curator

\begin{abstract}
Zipai, literally 'self-shot', is the Chinese word for 'selfie', and it indicates both the action and the product of taking a picture of oneself. This paper presents an account of the "ways of working" through which the authors - a media anthropologist and a performance artist - negotiated a collaborative approach to zipai. The essay begins with a discussion of contemporary practices of self-representation on Chinese digital media, arguing that the zipai uploaded by Chinese users on online platforms can be understood as locational and relational self-portraits, a media-specific genre of vernacular photography. It then proceeds to consider the ethical implications of appropriating vernacular photography for artistic and ethnographic representation, proposing to adapt the practice of filtering as an ethical intervention. After an overview of contemporary works by Chinese artists and photographers engaging with the aesthetics of zipai, the essay concludes with a reflection on the possibilities of collaboration between art practice and media anthropology.
\end{abstract}

\section{KEYWORDS}

selfies, vernacular photography, digital media, art practice, China 


\section{Introduction: From Chinese selfies to relational aesthetics in art and anthropology}

自拍的拍 拍到世外

自拍的拍 拍到发呆

('Taking selfies, to get out of this world Taking selfies, to fall into a daze')

(Li 2014)

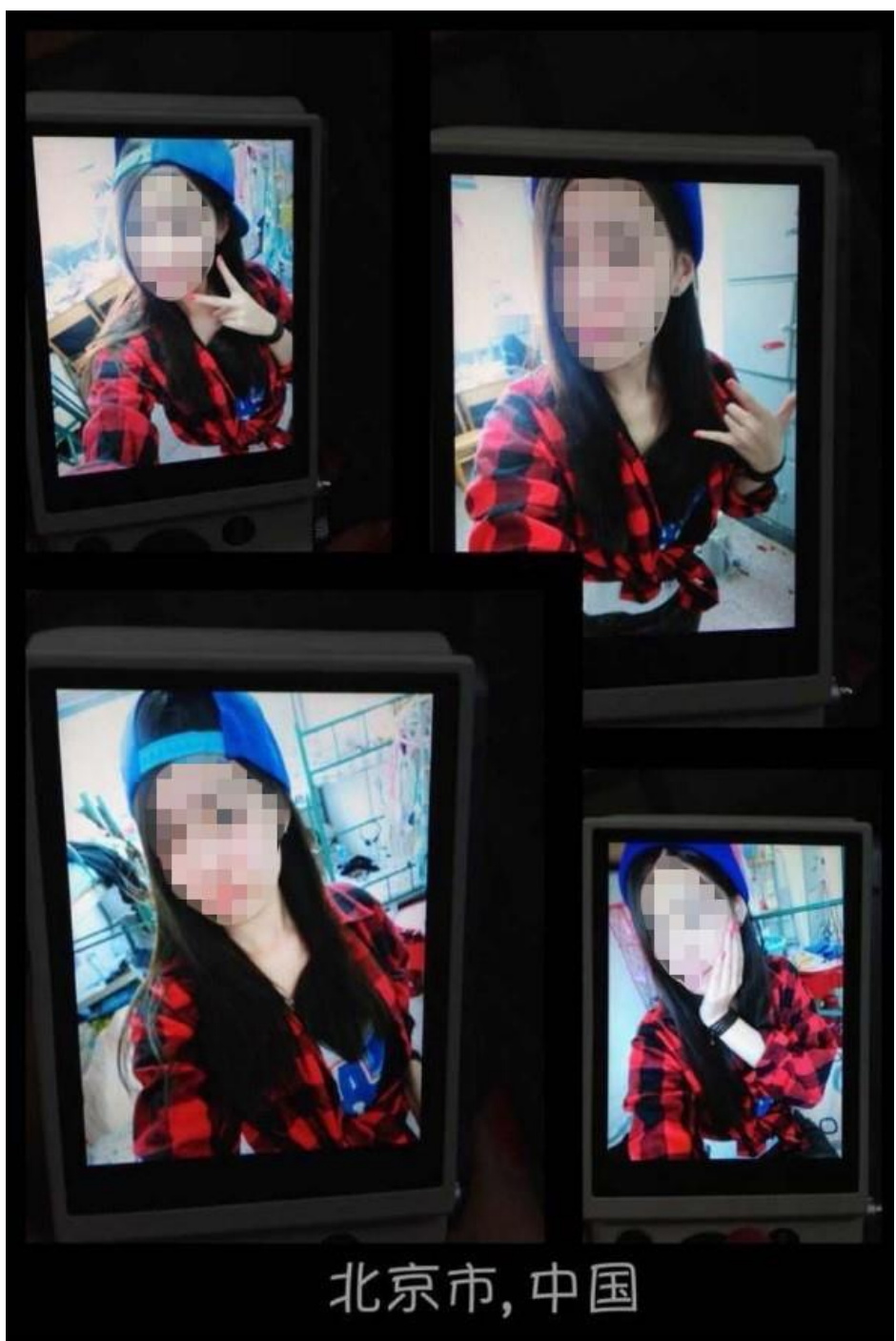

Figure 1. "Beijing City, China" - a photo collage of zipai (selfies) shot and displayed on digital camera, used as a WeChat profile photo: a media ecology in miniature. From Proksell's collection of public WeChat selfies (pixelated).
A light tap on the capacitive screen of your smartphone, right above the green icon containing two overlapping speech balloons with stylized eyes, the iconic logo of the WeChat app. A dark splash screen, for a second - the black silhouette of a young man standing on the edge of a cliff, watching the planet Earth float in space - then: "Messages", and a list of nicknames with square avatars on their left. Some of them jump to the top of the list accompanied by chiming notifications, marked by little red counters indicating the number of unread messages. A leftside swipe to the "Discover" menu, and here is the "People Nearby" function. You tap on the screen: "Looking for WeChat users nearby..." Another list: "Within 100 meters: Cathy Fang, 张志 明，Nelson, Miranda. Within 200 meters: yan., Mei, Kc, Alan Chen, David, E_N, Jun, $\delta$ 笨鸟 $\delta$. Within 300 meters..." The faces of strangers using WeChat in a $1 \mathrm{~km}$ radius from your geographical position gradually fill the grey avatar boxes on the left side of each nickname. With one more tap on the screen, one profile that caught your eye reveals its details: all you can see is a nickname, some photos, a location (Greenland, quite absurdly), and a "Send greeting" button. You tap on the profile picture first, opening it fullscreen. It's a zipai, a 'self-shot', a selfie. 
This was a description of the practice of casually browsing nearby user profiles on WeChat, the mobile social contact app most widely used in Mainland China for instant messaging, social networking and chance encounters. The practice of browsing user profiles is at the center of this essay, written in collaboration by a media anthropologist researching public self-presentation as a platform-specific genre of Chinese digital folklore, and a visual artist exploring the aesthetics of local media ecologies through the functions of WeChat. Fig. 1 is a perfect example of these media ecologies: a girl takes several pictures of herself with a small digital camera, trying different poses and angles, then uses her mobile device to take pictures of the digital camera screen itself as it displays these photos, then arranges four of them as a collage through a photo editing app on her smartphone, adding the caption Beijing shi, Zhongguo ('Beijing City, China'); eventually, she posts the captioned collage on her WeChat profile, visible to anyone browsing the app's locational search function in the vicinities. This image, like many other genres of usergenerated content, is an artifact emerging at a specific intersection of self-fashioning, digital devices, imaging software, online platforms, locality and sociality.

One of the authors of this paper, Michelle Proksell, lives and works in Beijing and has a background in portrait photography and curation of digital art. In her current art practice, she experiments with self-representation using different alter egos. The first one she performed as, Shelly $\mathrm{P}$, is a character "obsessed with herself and public image on social networking sites," who "uses the technology of present day [...] to add her image to the infinite pool of general female content online" (Proksell 2014). The most recent one, DongXi DongXi 东西东西 (translatable literally as both 'East West East West' and 'Something Something') is "a collective alter ego with a lost face", a "cultural hybrid" created in collaboration with local artist Ophelia S. Chan, whose first performance piece was developed along the research for this essay. Art practice, and its ongoing processes of creative research and data collection, are a fundamental component of this paper.

Given its collaborative and processual nature, this essay advances multiple arguments at once. In the following sections, we illustrate the parallel lines of inquiry that, starting from a voyeuristic peek into an app's affordances and user practices, lead into Michelle's ongoing collection and aesthetic analysis of thousands of WeChat selfies from nearby public profiles, and end (provisionally) into a piece of performance art. The first section of this paper provides a definition of selfies, which we understand as a media-specific genre of vernacular photography, and summarizes the sociotechnical context of self-representation on WeChat. The second section discusses the ethical implications of appropriating vernacular photography for artistic and ethnographic representation, proposing to adapt the practice of filtering as an ethical intervention. The third section, based on interviews and discussions with practitioners, consists of an overview of contemporary works in Chinese art and photography that take selfies, or self-representation more generally, as a central theme. In the conclusion, we discuss DongXi DongXi's debut performance in Beijing and the write-up of this paper as an example of how visual art and media anthropology can inform each other not only retrospectively and at a distance, but also through a sustained processual engagement between the respective "ways of working" (Schneider \& Wright $2013,1)$ and the self-reflexivity supported by relational aesthetics of collaboration $(2013,9)$. To highlight this point, the textual sections of this essay are counterpointed with visual materials that are either sampled from Michelle's collection of vernacular self-portraiture on WeChat, or kindly 
provided by the interviewed practitioners to illustrate their own works; these materials should be taken into consideration as integral parts of the authors' arguments.

Our aim is to provide a glimpse into the creative practices of self-representation of Chinese digital media users, and into the ways visual and performance artists engage in a dialogue with these aesthetics. We argue that it is the role of both media anthropology and art practice to display, describe and operationalize contemporary forms of vernacular photography and everyday self-representation on digital media: As Huang (2010) suggests in her study of family portraits in China, "a history of contemporary Chinese visual cultures will have to come to terms with this body of private artifacts" $(2010,686)$. Fig. 2 shows an example of how artifacts from everyday life enter contemporary Chinese visual culture as aesthetic elements of the selfie: anti-pollution and sanitary masks are integral part of these self-portraits, while superimposed comments often index the mask as a signifier for the care of the self and the other - either against air pollution or contagious illness.

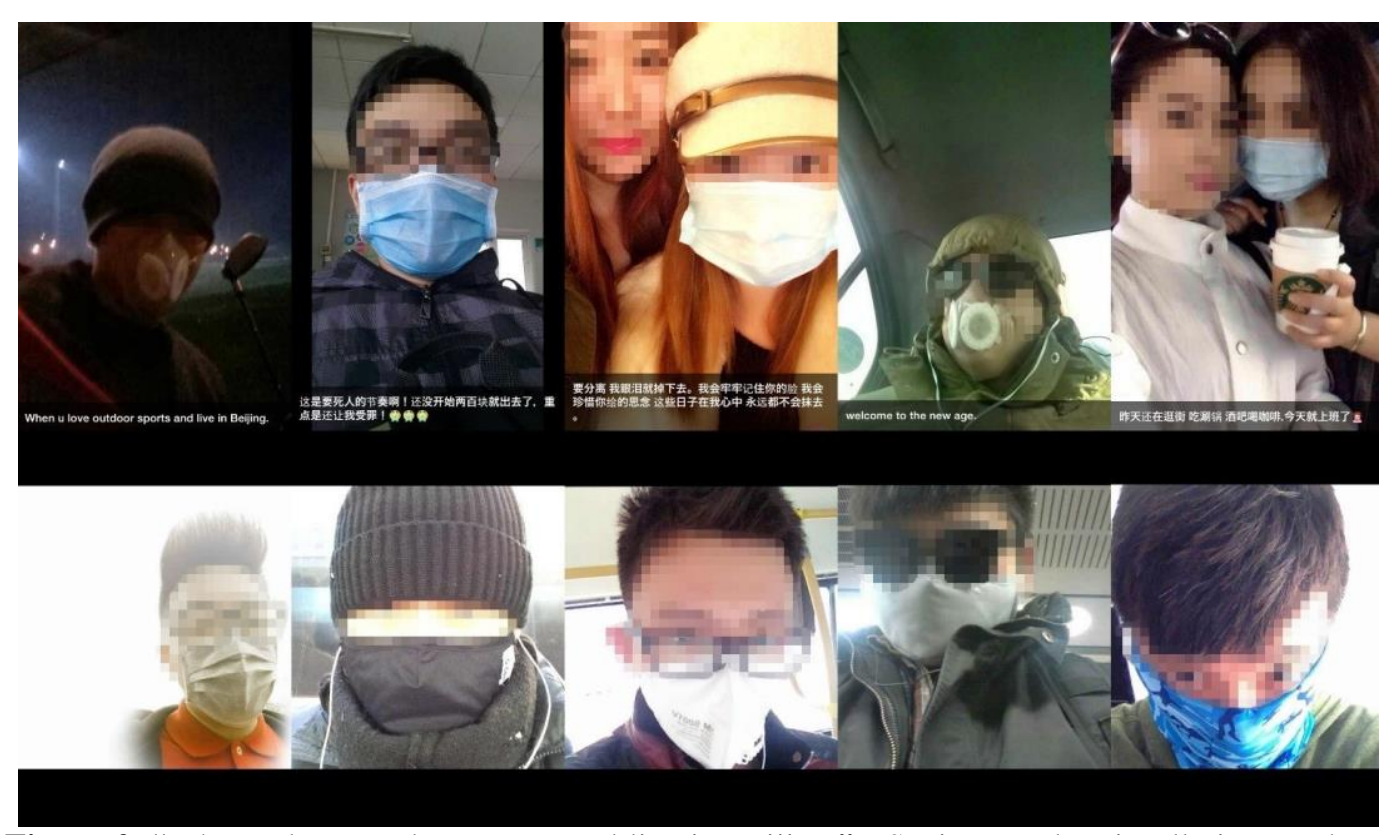

Figure 2. "When u love outdoor sports and live in Beijing." - Sanitary and anti-pollution mask as visual statements of care for the self and others. From Proksell's collection of public WeChat selfies (collage, pixelated).

\section{Unpacking the WeChat selfie: Relational self-portraiture in the age of locational media}

As we write this essay, selfies are no longer a novelty in the fast-paced ecology of digital media genres (Wendt 2014, 7). The term "selfie", defined as "a photograph that one has taken of oneself, typically one taken with a smartphone or webcam and uploaded to a social media website" has been chosen by the Oxford English Dictionary as the word of the year 2013 (Oxford Dictionaries 2013), and "every major social media site is overflowing with millions of them" (Tifentale 2014, 5). While being predictably targeted by moral panics and media scares (McKay 2014; Ryan 2013) selfies have possibly become "the most prevalent popular genre ever" (Saltz 2014), and their 
production and dissemination has been theorized in the broader domain of sociotechnical practices of self-representation and self-fashioning (Rettberg 2014).

We take as a starting point the idea that the selfie, rather than a cultural phenomenon to be interpreted in isolation, is more theoretically and methodologically productive when understood as a popular genre of vernacular media production, a performative visual practice of the everyday founded on an "autoportraitistic pact" (Hölzl 2009, 43) and inextricably tied to the affordances of portable imaging devices and image-sharing online platforms (Tifentale 2014, 3). As famously argued by Bourdieu (1990), even a private, mundane and seemingly trivial practice such as amateur photography can provide material for social scientists and should not be ignored or dismissed by researchers. In fact, "in turning towards ordinary consumption, the pervasiveness and dynamics of photography can be examined from the group up as a set of meaningful social practices" (Bourdieu 1990, 47); it seems to us particularly relevant to examine an emerging genre of amateur photography in times when its pervasiveness is amplified by ubiquitous digital imaging devices (Hand 2012) and networked social dissemination (Poster 2011). As Hand argues in his Ubiquitous Photography,

the weaving of photographies - as images and ideas, as devices and techniques, and as practices - into every corner of contemporary society and culture produces quite a different scenario from that envisaged during the late twentieth century. Where many once imagined a future of digital simulation and virtual reality, we now arguably have the opposite: the visual publicization of ordinary life in a ubiquitous photoscape. $(2012,1)$

It is in this ubiquitous photoscape of ordinary life that we locate the performative and social practice of taking and sharing selfies. Hogan \& Wellman (2014) describe how user profiles on SNSs encourage users to share a representation of "a dynamic and selective digital self that can link to and communicate with others" $(2014,56)$, which the authors call "relational self-portrait" $(2014,54)$. In the context of an "emerging interplay between the digital camera and the phone, smartphone and cameraphones, particularly in the Asian economies, where over 80 per cent of cell/mobile phones are now also image-capture devices" (Hand 2012, 3), selfies featured in WeChat profiles can be understood as a genre of relational self-portraiture inflected by the specific features of the platform.

Selfies have entered Chinese popular culture along with camera phones. Known as zipai, they imply a repertoire of poses, aesthetics and social rituals, and have spawned a flourishing market of mobile accessories such as selfie sticks and remote controls (see Fig. 3). Predictably, the English-language press tends to highlight the quirkier side of the practice - reports on the trending of 'armpit hair selfies' are a case in point (Nelson 2014) - yet in China zipai are taken, shared, commented upon, and predictably satirized for their omnipresence just like anywhere else. A joke some informants shared with us during the writing on this paper was a riff on the recent blockage of Instagram - the Western selfie hub par excellence - in Mainland China: 


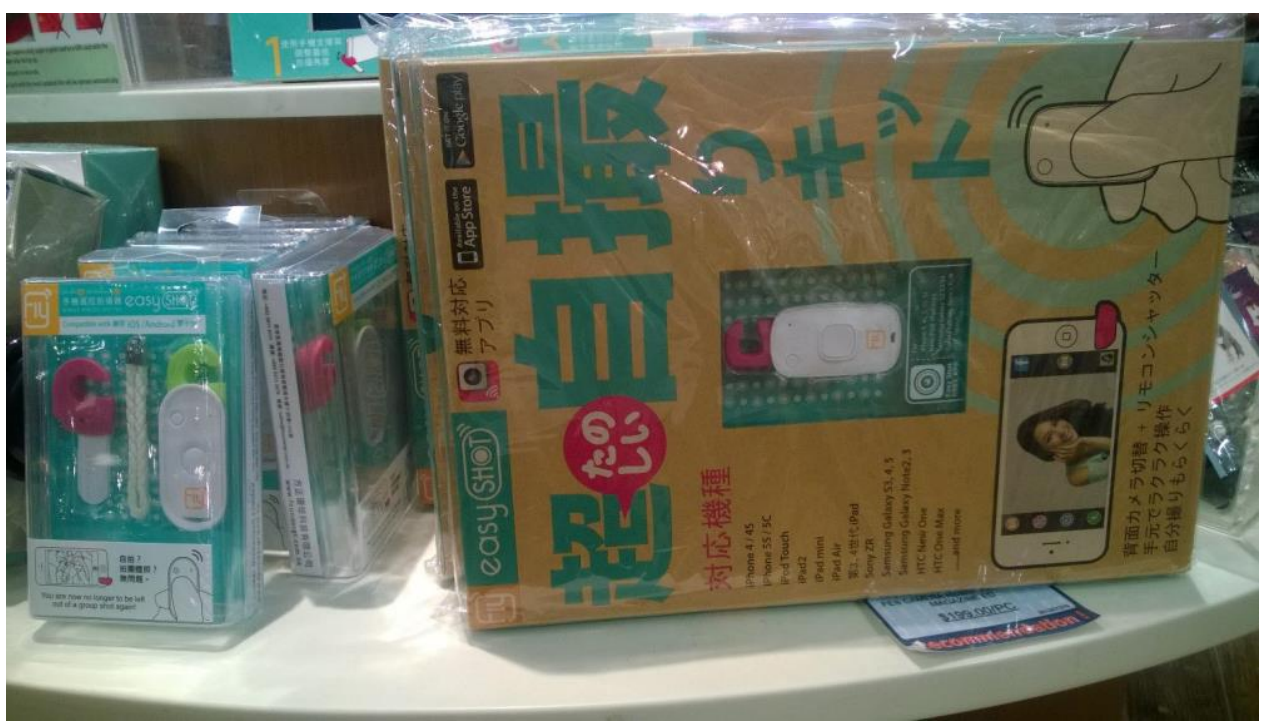

Figure 3. Japanese-design remote controls for shooting more natural selfies with mobile devices, for sale in China. Photo by the authors, 2014.

ins [Instagram] has been blocked. Actually it is the government warning you about the dozens of zipai you take every day: if you keep them behind closed doors in your WeChat friend circle or QZone it's no big deal, but please don't go clog up the platforms of foreign friends. (personal communication 2014)

This joke is a small anthropological essay (Critchley 2002, 65): while downplaying and ridiculing the Chinese authorities' decision of blocking Instagram and implying it was a move to prevent foreign services being flooded by Chinese selfies, it also reveals the hierarchies of distinction applied to local platforms and the respective perceptions of privacy. In fact, research from just a few years ago claims that cultural factors made Chinese users less willing than American ones to share personal information online. Through a comparative sampling study, Ye (2011) finds that " $51 \%$ of Chinese users used a real photo of them as an avatar on MySpace, while this percentage of users for Americans is 87\%" $(2011,126)$. Yet, as Wallis notes in her study of female migrant workers, camera phone users have been experimenting with self-presentation even before the popularization of mobile connections and SNSs (Wallis 2013, 131), and the social role of these photographs has been changing along with the affordances of different platforms:

During the initial research period, there was no Chinese equivalent of Flickr, and women did not participate in any sort of social networking site that would have allowed them to upload photos to the web. On return visits in 2009 and 2010, many women were accessing the Internet, mostly QQ, on their phones and some were uploading images to QQ's Qzone. (Wallis 2013, 222-223)

The popularity of WeChat (in Mandarin Weixin, literally 'micro-letter') in Mainland China is partly explained by the established position of Tencent, its parent company, but is also undeniably boosted by the restrictions on competing apps like Line or KakaoTalk (Lee 2014). WeChat was released in January 2011 as a simple text and voice messaging service for mobile devices, but has been since then steadily upgraded with new functions (like games, machine translation, broadcasting, video calls and micropayments), integrating elements of popular 
American apps like Instagram, Facebook or Vine. As a result of this integration, WeChat user profiles have become akin to personal pages, the multimedia "Moments" shared with one's contacts accumulate in dynamic feeds allowing comments and likes, and the GPS and networkbased locational capabilities enable the discovery of nearby strangers who are using the same app. With its almost 400 million users (Danova 2014) WeChat can be considered as a digital media ecology (Fuller 2005) in its own right, with some speculations even seeing it as the embryonic stage of a Chinese "homegrown" operating system (Lancette 2014).

Given the closed nature of the social networking enabled by this mobile app, the absence of a Web-based front end, and the degrees of privacy and searchability that the app allows its users, the selfies used as WeChat public profiles might be better conceptualized as locational and relational self-portraits. As Fig. 4 illustrates, profile pictures on WeChat embed mobile technology in self-representational statements: "Just as the camera taking the photograph is visible in digital self-portraits taken in a mirror, so early photographers often included the tool of their trade in their self-portraits" (Rettberg 2014, 8) - here it is the smartphone, as branded tool of the trade, at once camera and communication device, which becomes an element of the locational self-portrait.

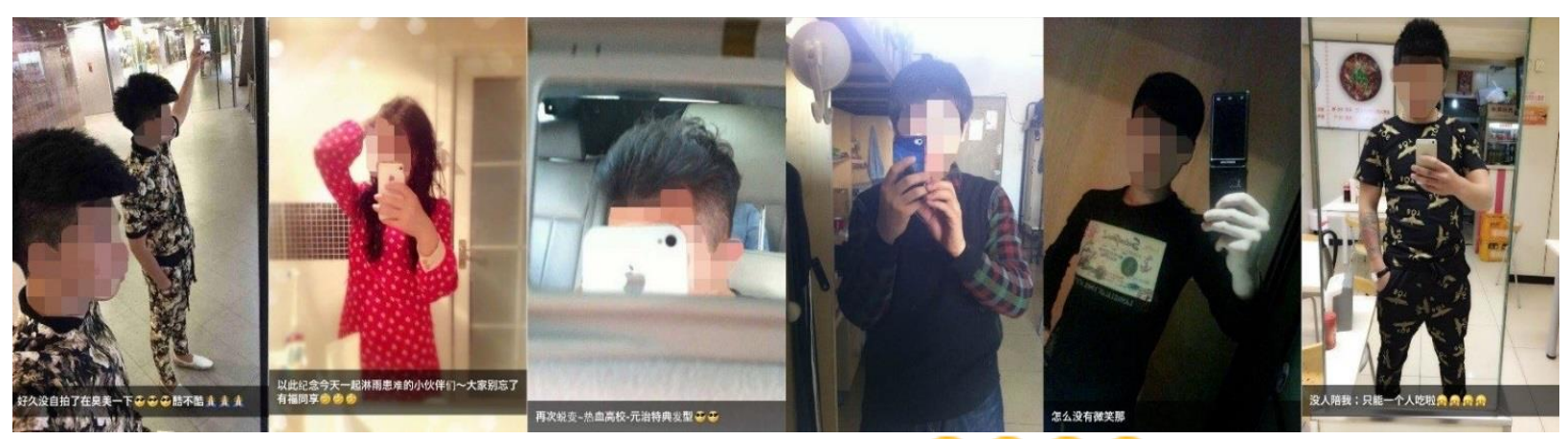

Figure 4. "No one keeps me company; I can only eat by myself self-representation in mirrored selfies. From Proksell's collection of public WeChat selfies (collage, pixelated).

\section{Filtering representation: The ethics of appropriating vernacular self-portraiture}

The collection of data from public social media profiles, even when conducted qualitatively, and especially when this data is then re-presented in either anthropological writing or artworks, raises several methodological and ethical questions: How to sample something at the same time as personal as an individual self-portrait and as pervasive as a ubiquitous media genre? What does the reliance on found images imply for subsequent anthropological and aesthetic analyses? How can artists and ethnographers participate in media ecologies that allow anonymity and voyeurism, and rely on participants that have no way of knowing what they are participating in? What about informed consent and disclosure?

All these issues have been given centrality with the visual turn in the human and social sciences (Spencer 2011, 2): if "seeing comes before words" (Berger 1972, 7) and "every image embodies a way of seeing" $(1972,10)$, the "omnipresence of photographed images" (Sontag 1977, 3) in contemporary societies not only provides an interpretive grammar, but "even more importantly, 
an ethics of seeing" (ibid.). Research on selfies, as it is the case for analyses of other genres of pervasive digital media content, seems to encourage quantitative data collection and computational processing: Lev Manovich's Selfiecity is a stunning example of this methodology (Tifentale, 2014, 3). This paper describes a diametrically opposite approach: the collection of selfies from WeChat public profiles happens through an artist's long-term, first-person participation in the platform, and the analysis is conducted with the contribution of an ethnographer studying Chinese digital media. Rather than framing selfies as cultural texts (Wendt 2014), our aim is to present these practices of self-representation as a contemporary example of vernacular photography. This, in contrast to statistic-driven cultural analytics or interpretive critiques, helps unlocking "the vast expressive potential of visual representations that opens up the way to scholarly argumentation and new avenues of expressing the unspeakable and unquantifiable [emphasis added]" (Luc Pauwels, as cited in Spencer 2011, 18).

At the time of writing, one of the authors (Michelle) has already collected nearly 3,000 selfies throughout two months of daily use of the WeChat mobile app installed on her iPod touch: the mobile device, carried around Beijing as an exploratory tool, is "a powerful prosthetic" (Hein, O'Donohoe \& Ryan 2011, 258) for ethnographic research. The ongoing participatory collection is driven by the idea that selfies are "cumulative self-presentations" (Rettberg 2014, 35) and that "like most self-representations in digital media, profile photos are part of a serial and cumulative visual communication" $(2014,40)$ in its own right. Michelle's main activity on the app, besides interacting with a handful of personal contacts, has been browsing public WeChat user profiles, in different locations around Beijing and at different times of the day, through the "People Nearby" function described in the introduction: by chatting up strangers and saving the selfies she found in user avatars and public image galleries, she engaged in a long-term locational exploration of the cumulative aesthetics of the genre. In her words:

Because I was using my iPod touch to access WeChat, I couldn't rely on a data connection and I was limited by the availability of Wi-Fi access points throughout my daily movements. I'm pretty sure this influenced the collection of selfies, since I was precluded from browsing nearby contacts while commuting or walking around. In fact, most of the selfies I have collected so far come from profiles I found (or who found me) while I was sitting at home, in my workplace, in cafes, restaurants, bars or friends' homes, mostly inside the 2nd Ring Road of Beijing.

Collecting WeChat selfies from public profiles does indeed provide a privileged window into spontaneous practices of mobile digital self-portraiture by "using the participants' own photographs" (Croghan, Griffin, Hunter \& Phoenix 2008, 346), but it also creates a number of problems regarding the ethics of seeing. The first problem is the flattening of fluid and cumulative repertoires of self-presentation (Rettberg 2014, 43), unavoidable when making decisions about the persistence of images extrapolated from user profiles and publishing them in an academic paper with no right to be forgotten - a long-standing quandary in ethnographic research (Clifford 1986). The second problem is informed consent, since only an infinitesimal part of the people contacted would respond to friend requests and be interested in articulating their views about their personal fronts and agree to the collection and reproduction of their public images (Hudson \& Bruckman 2004). A third and obvious problem is at the level of privacy and identity protection: selfies are by definition personal self-representations, so displaying examples 
from the collected materials without infringing on rights to privacy and confidentiality requires a certain degree of anonymization. As boyd \& Marwick warn, "just because teens are socializing in a public setting doesn't mean that they want to be public figures nor does it mean that they want to be the object of just anyone's gaze" (2011); this is probably even more the case in China, where users prize pseudonymity and the careful management of their online identities (Farrall \& Herold 2011).

To find the most ethical way of discussing selfies on public WeChat profiles, we follow Markham \& Buchanan's suggestion of understanding ethics as a process-oriented approach rather than as a prescriptive set of rules $(2012,3)$. In the specific sociotechnical context of WeChat, all the visual data collected was publicly available to anyone in possession of a digital device running the app in the vicinities of the profiles found with each "People Nearby" search. Moreover, it is arguable that, given the flood of friend requests that public profiles receive, users would be proactive and conscious about the shared content visible through locational searches of their own profile (Tencent Inc. 2014). As Michelle recalls, this experience is also strongly gendered:

most of the people contacting me were local or foreign men who thought I was a young Asian woman - wanting to know where I lived, what I was doing, asking me if I was a student and nearly always telling me that I was beautiful or, after finding out that I was American, that my Chinese was quite good.

By being actively made available to public browsing through multiple, fine-tuned settings for selective privacy, user profiles on WeChat can be conceptualized as personal fronts for the presentation of purposefully crafted selves to other users (Goffman 1990, 13; Rettberg 2014, 40), a function similar to what Hogan \& Wellman (2014) assign to SNS profiles: "Portraits and personals coalesce in the modern SNS profile, as profiles include both photos that signify the individual (often next to messages on the SNS), and selective revelations about the self that a user considers appropriate to that site" $(2014,56)$. In light of the sociotechnical context of the app, we decide to consider the sparse personal information collected on WeChat public profiles (a nickname, some pictures and a location) as a media-specific form of public display (Allmark 2011, 178):

everyone took photographs and was used to featuring in posed or unposed pictures [...] all these photographs [...] represented and recorded performances. What was important here, however, was that participants' pictures represented performances to one another, rather than to the researcher in particular. (Hein et al. 2011, 266)

As a case in point, specific genres emerging from the collection of selfies hint at differentiated forms of publicity and audiences: Fig. 5 collects some of the 'merchandise selfies' with which young women advertise skin care and make-up products to nearby WeChat users through highly constructed visual artifacts - promotional shots augmented by explanations, comparisons and testimonials. 


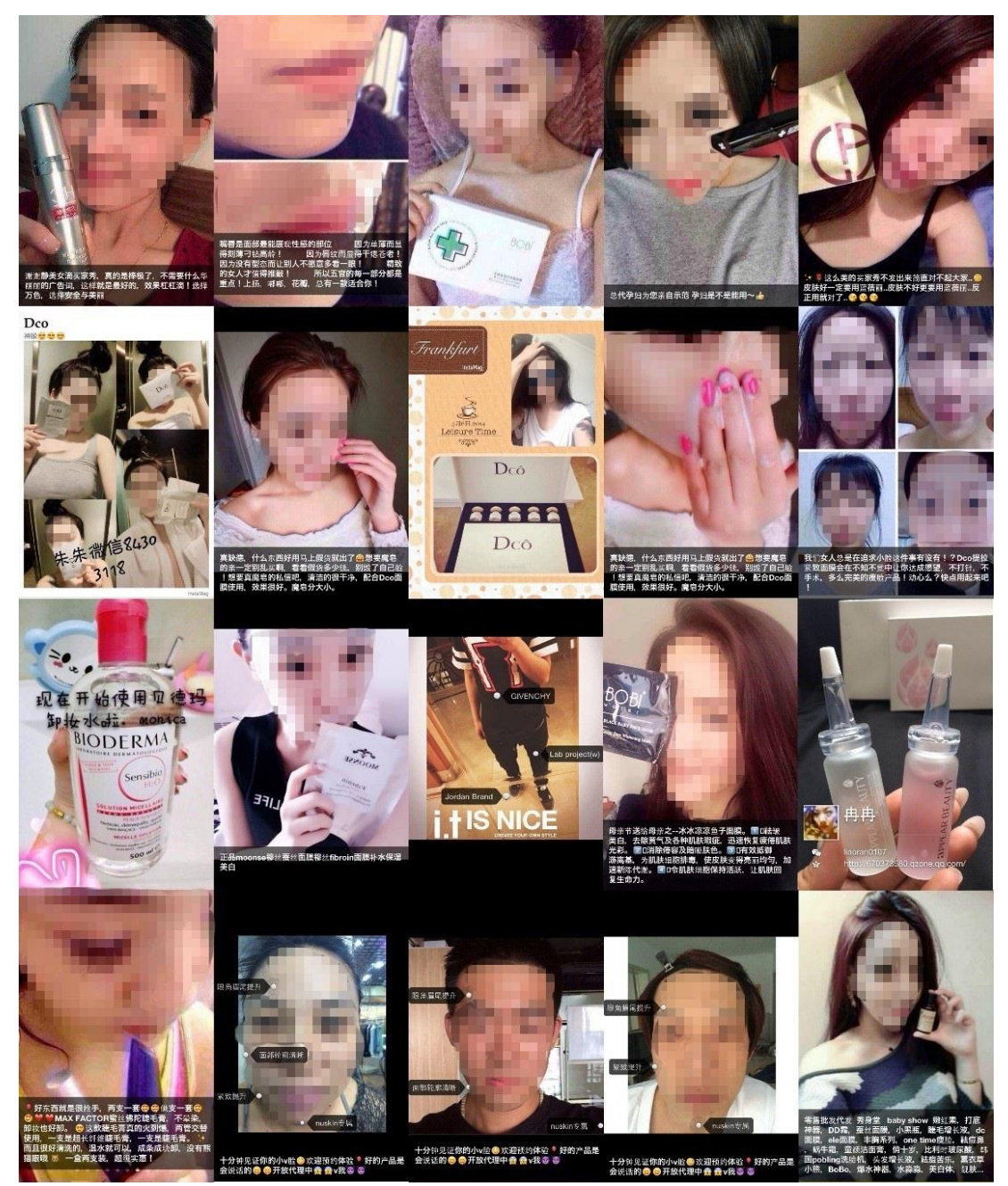

Figure 5. Selfies with merchandise: "There were only a handful of times I was actively contacted by women; most of them were product endorsers with galleries filled of heavily captioned promotional selfies" (Michelle). From Proksell's collection of public WeChat selfies (collage, pixelated).

The ethics of representation need to be parametric and context-sensitive. Having taken into consideration the nature of the media and the reasonable expectations of users, and given the unsystematic modality of data collection, we feel that including a selection of selfies from the shared content available on WeChat public profiles is a necessary addition to this paper. Yet, although they can be thought of as found images of public performances, a line has to be drawn between their expository function and the violence of persistence and appropriation. And to draw this line, we turned back to the collected selfies: many users, when uploading photos of themselves with friends or colleagues, spontaneously used photo-editing apps to blanket out, blur or pixelate the faces of other people included in the selfie. The examples collected in Fig. 6 show a similar kind of authoring practice, as the users mask and augment their selfies with playful overlays: glasses, stylized moustaches, big noses, cat whiskers, ribbons and flowers. All these choices, reflecting respect for other people's control over their own self-representation - and the play on one's own - fall under the rubric of what Rettberg (2014) calls 'filters'. 


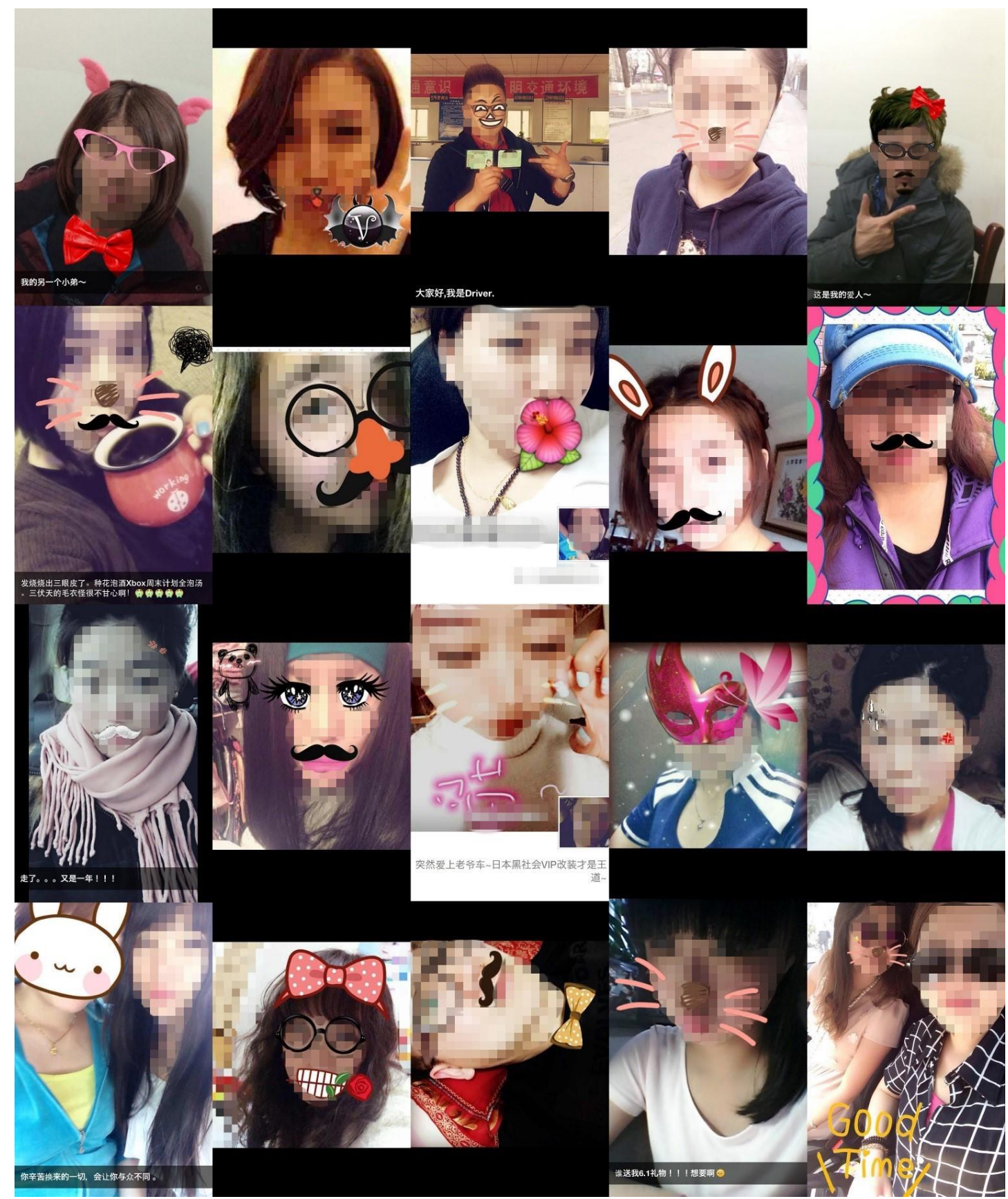

Figure 6. Authoring representation: WeChat users' practice of selective masking and playful anonymization through photo-editing apps. From Proksell's collection of public WeChat selfies (collage, pixelated).

In her analysis of self-fashioning through technology, Rettberg deploys the word 'filter' as "as an analytical term to understand algorithmic culture" (2014, 20). Similarly, Wendt (2014) observes how filters transform selfies into complex digital objects layered with representational choices $(2014,10)$. We propose to push this reasoning one step forward, and conceptualize the application of photographic and software filters as an ethical heuristic grounded in actual user 
practices. We decided to filter all the facial features from the selfies provided in this essay with the pixel mosaic function of the same app used by most Chinese users - Meitu Xiuxiu. This choice is grounded on the tools and aesthetics popular among local users, and coincidently helps pulling the reader's attention away from the specific appearance of the individuals portrayed, highlighting instead the vernacular strategies of representation used in these selfies. Obviously, as any form of anonymization, this specific technique comes with its tradeoffs: the selfies' authors might feel depersonalized and deprived of their authorship, and the pixel mosaics might remind of media representations of crimes involving minors or censored adult video.

Ultimately, this is a clear case of the clash between the ethical paradigms of the social sciences, the authorial focus of the humanities, and the repurposing aesthetics of much of contemporary art and curatorial practice. The ways in which digital media artifacts can be considered at once data, found images and art, and the contrasting position of digital media users as both research subjects and amateur artists (Bruckman 2002) require specific and contextual choices. As Rettberg observes, "perhaps much of the discomfort we see surfacing around selfies is related to this: we are still bound by these social norms but technology allows us to photograph so much more than when the social norms for photography developed" $(2014,53)$. It is in this context of shifting discrepancies between social norms and technologies that it becomes important to look into user practices, especially as

traditional efforts by teenagers to change their appearance and image give way to the conscious creation and curation of online identities, as well as the revision of existing norms (for example, around the use and re-use of thirdparty created content). (Nash 2014, 70)

Our choice of applying a form of image filtering grounded in the social norms of the specific sociotechnical context under research is an imperfect example of relational ethics, negotiated between authors from different backgrounds, informants, research subjects, and publishers. Like other methodological aspects of an interdisciplinary project, they are "probing, exploratory, and often remain fragmentary and open-ended in their results" (Schneider \& Wright 2013, 4).

\section{Representing representation: Appropriating selfies in art and photography}

Selfies have changed aspects of social interaction, body language, selfawareness, privacy, and humor, altering temporality, irony, and public behavior. It's become a new visual genre - a type of self-portraiture formally distinct from all others in history. Selfies have their own structural autonomy. This is a very big deal for art. (Saltz 2014)

Today's selfies are different in that they are a true vernacular genre. They are rarely exhibited in art galleries; instead they are shared with friends and followers on social media. (Rettberg 2014, 9)

After sketching the sociotechnical context of WeChat selfies and debating our ethical concerns regarding their collection and appropriation, we turn to investigate how selfies, and vernacular practices of photographic self-representation more generally, have been included in contemporary 
works of Chinese art and photography. Selfies have already entered art museums mostly in the works of young artists operating in the context of Euro-American digital media cultures. Petra Cortright's webcam performances are a perfect example of this, as her self-shot body is "obfuscated through cheap digital effects, bombarded by virtual snowflakes, tears and rainbows and pushed to a point of abstraction while cute, kitschy iconography compromises its visibility" (Vasey 2013, 7). Yet Cortright's practice follows a very personal reinterpretation of feminist selfportraiture, and remains concerned with an individual, self-reflexive production of artworks. Our interest for archives of found digital images and their curation raises a different question: how has Chinese vernacular self-portraiture been collected and re-elaborated by visual arts practitioners?

Our first step was discussing selfies with Thomas Sauvin from Silvermine Collection. The Silvermine Collection is an archive of modern and contemporary vernacular photography, which Sauvin describes as a "long series of accidents" (personal communication 2014). Sauvin set up the archive in in Beijing in 2009 and has collected, by the time of writing, almost one million negatives shot between 1985 and 2005, of which more than half have already been processed, scanned, viewed and numbered. Given the focus of the archive on analog photography, selfies are virtually non-existent as a genre, with the exception of a very peculiar kind of photographs, which Sauvin has termed "accidental selfies": self-portraits captured by people who were adjusting or testing the camera or who needed to shoot the last exposure of a film roll. A hypothetical history of the selfie in China could begin from these quirky accidents of vernacular analog photography, some of which are shown in Fig. 7.

According to Sauvin, one of the earliest projects involving a camera phone in China is One Day One Photo by Jiangxi native visual artist Lei Benben, a mobile image diary compiled since 2007 from photographs which the artist describes as having "a 'special atmosphere,' embodying something of a "natural law of things"" (Sanderson 2011). Browsing the month-based albums of pictures taken with her Lenovo camera phone, it is not uncommon to come across selfies, hinting at a connection between the emergence of mobile digital imaging and the reflexive turn of vernacular photography.

Similar dynamics emerge from the work of Da Gua, a Beijing-based TV and media production graduate who compiles several blogs and magazines often featuring selfies shot with her iPad: "I'm not sure about when I started collecting these selfies... maybe it started from the first selfies I posted on Weibo, about one or two years ago" (personal communication 2014). Da Gua's most recent project is a collection of selfies taken in McDonald's restaurants that include unaware patrons in the shot (Fig. 8).

I am just very interested in teenagers, and I love McDonald's since I think it is a place where whoever can go to eat something cheap and do anything they want - there are so many teenagers wearing their school uniform eating or dating here. I want to shoot them directly, but taking selfies like that is a better way. Maybe because I want to be a part of them while also realizing that I've grown older and I feel far away from that kind of life. (Da Gua, personal communication 2014) 


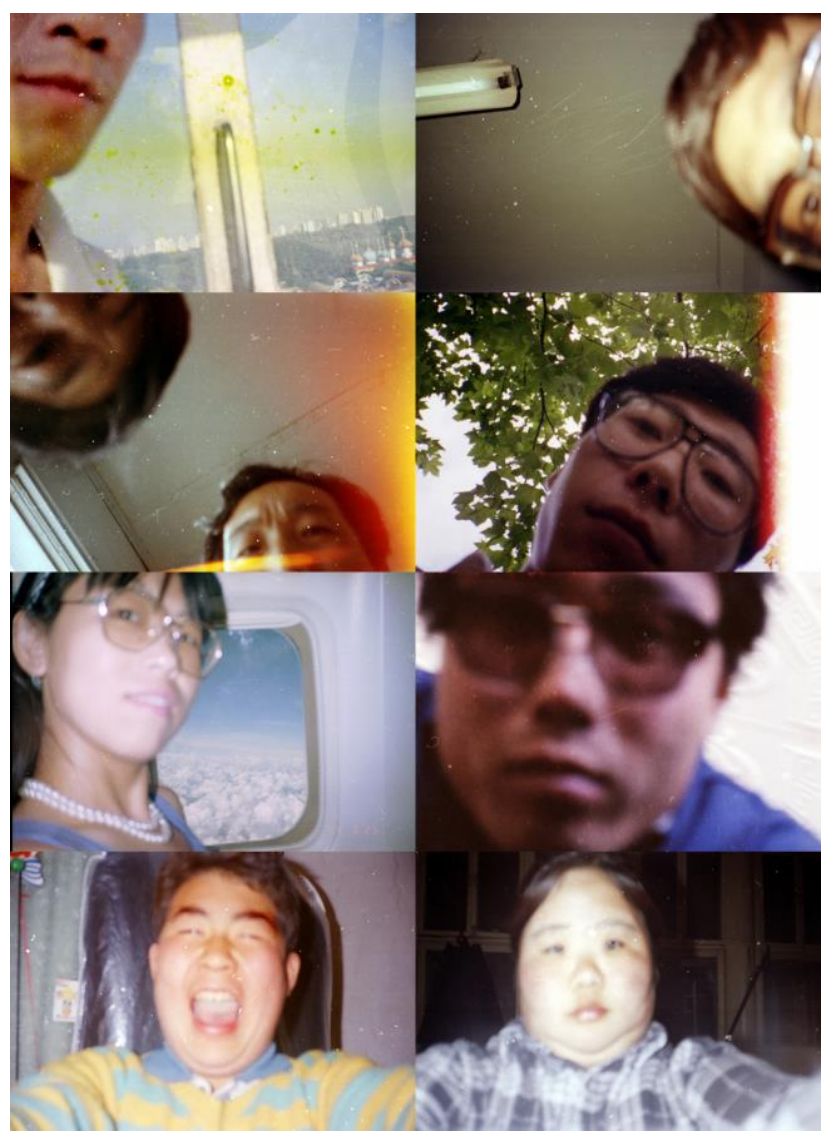

Figure 7. "Accidental selfies" from the Silvermine Collection, kindly provided by Thomas Sauvin (collage by the authors).

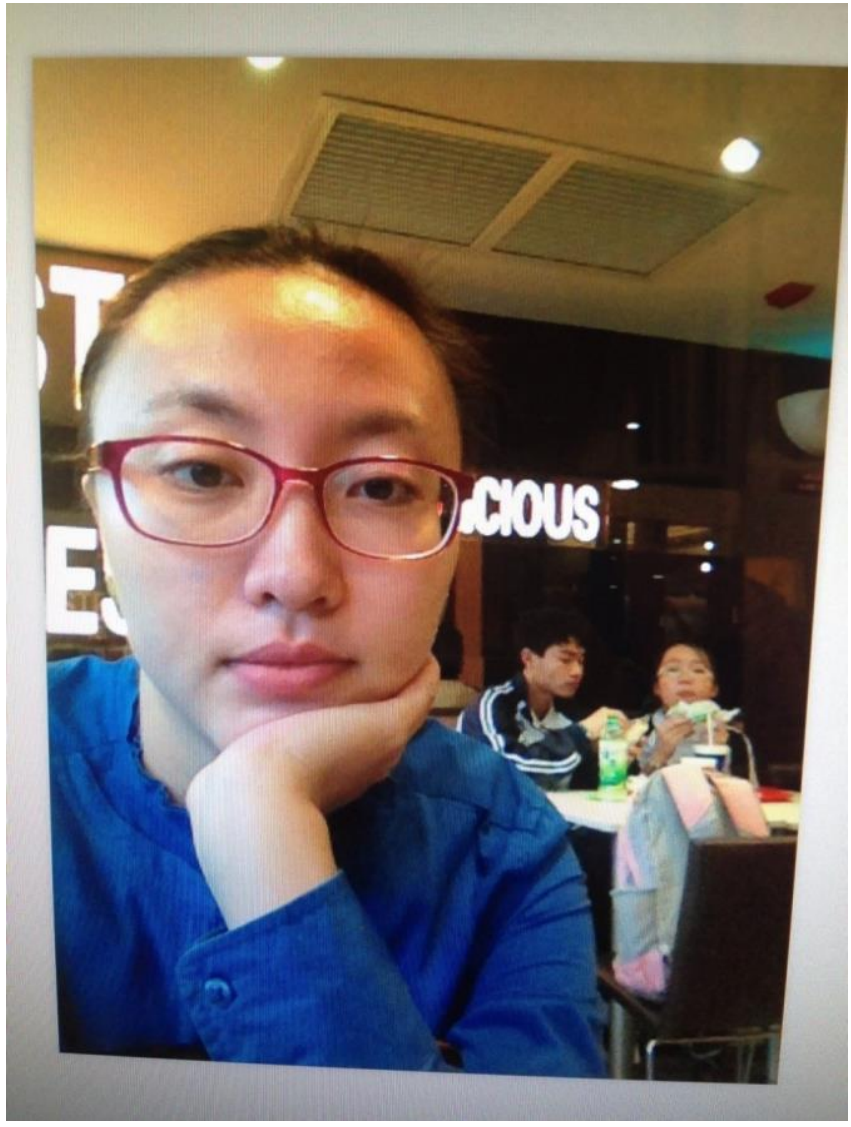

Figure 8. Selfie from Da Gua's McDonald's project, kindly provided by the artist. "I think selfies are interesting. They are a way of recording oneself. But at the same time they are also a way of creating something" (Da Gua, personal communication 2014).

Liu Zheng's Selfie project relies on a more systematic approach to documentary photography and archival practice, something he developed throughout his career as a traveling photographer on a mission to compile "a substantial reexamination of the Chinese people, uncensored and without political agenda" (Punj 2012). For this ongoing project, recently exhibited for the first time in Beijing, Liu delegates the actual photo-taking to volunteers: his WeChat and Instagram profile pages encourage other users to send him nude selfies for inclusion in the archive, stressing the centrality of the platform in both the production and dissemination of images (Fig. 9). "You can find some examples in my Instagram or WeChat image galleries, although they are watermarked. But they are just drops in the ocean, the collection I am putting together is much larger" (Liu Zheng, personal communication 2014). 


\section{ARTLIUZHENG}

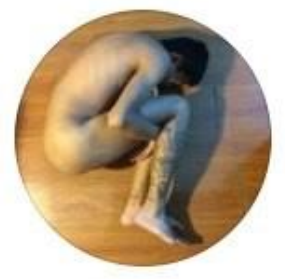

106

帖子
413

粉丝

编辑个人资料页

刘铮

艺术家刘铮网络互动项目《自拍》人体自拍志愿

者征集请加微信号：art-liuzheng ....Artist Liu

Zheng's art project $<$ Selfie $>$ nude volunteers

add me on wechat: art-liuzheng

www.artliuzheng.com

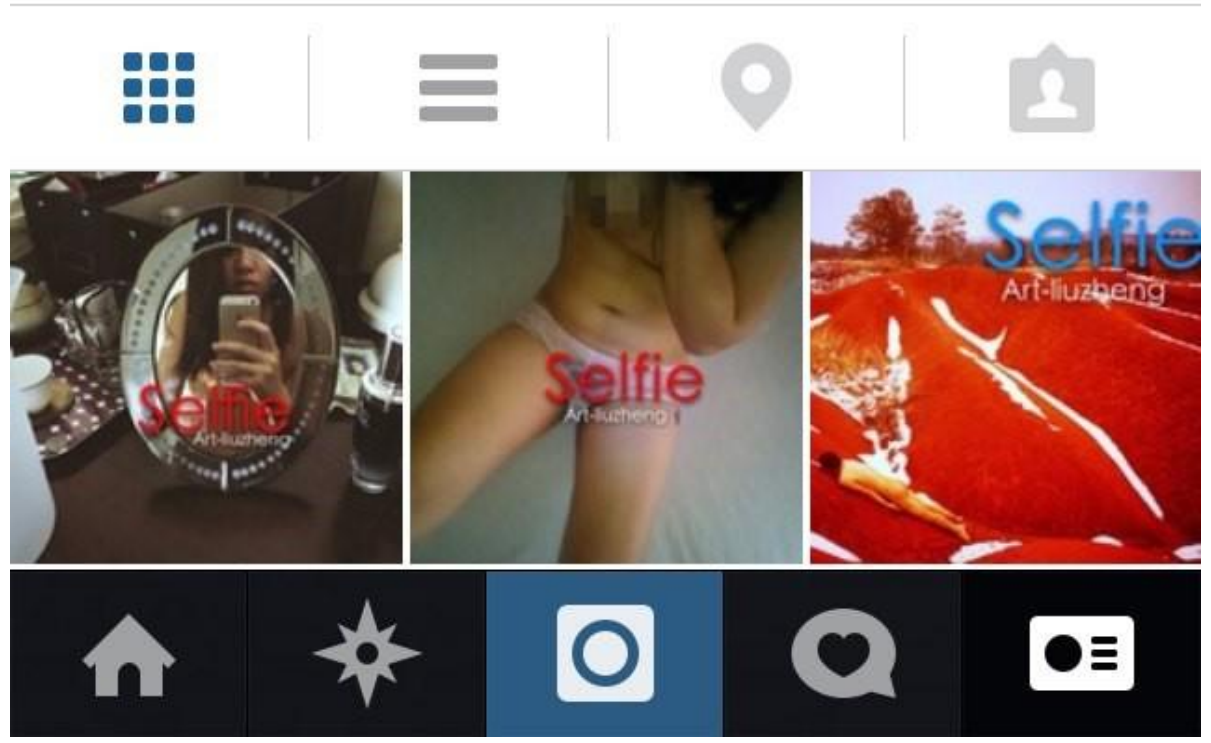

Figure 9. "Add me on WeChat": Liu Zheng's Instagram profile featuring Selfie's call for nude volunteers and three watermarked previews. Screenshot provided by the artist.

Social media platforms, WeChat in particular, are similarly central in the works of transmedia artist Michael Beets. While working in Shanghai on the production of SELF - A Smartphone Theater Experience, he explains the impact of locational social media on his own creative practice: 
WeChat had just come out, or rather was becoming increasingly popular. Everybody was downloading it and talking about the "People Nearby" function and how easy it was to find people, or for people to find you within a certain distance. It blew my mind that people were willing to share their personal information in such a free, and to a certain degree unrestricted, manner. (Michael Beets, personal communication 2014)

It is precisely through the "Look Around" function of WeChat that Beets has collected, along the course of three months, the photos displayed in Gallery of Dots - The Wei Xin Project (http://galleryofdots.com/), an "online experiment" that repurposes vernacular digital photography into web-based storytelling through an in-browser visualization. "I wanted to keep it digital", he explains: "These images were uploaded online in this weird infinite world, so I thought that representing each video by a dot in a space-like environment would be fitting" (Michael Beets, personal communication 2014).

The work of digital media artist Ying Miao presents a different approach, bringing the digitality of user-generated content back into the physical realm of devices and accessories. For her \#mememe, a mixed media installation exhibited in 2014, she assembled different models of Apple devices encased in personalized cases, an iPhone-shaped lighter, solar powered display pedestals, a selfie stick, and other paraphernalia representative of the contemporary ecologies of Chinese mobile media (Fig. 11). The images Ying Miao has chosen to be printed on the iPads and iPhones cases are all selfies she has found online:

it took me a long time to figure out what would be the best medium to print them on. Originally I was going to print them on canvas, then I saw some ads on Taobao of people offering to customize smartphone cases [...] I felt this was the best way to showcase the selfies because it duplicates the physical production of accessories - you customize your appearance in a selfie, then you customize your phone or your tablet with someone else's selfie... and then maybe you then take a selfie of yourself. (Ying Miao, personal communication 2015)

Ying's \#mememe is also an example of an artist incorporating vernacular practices of filtering in her work. After choosing the most suitable selfies to be printed on the device cases, she decided to alter them using the filters included in the popular image editing app Meitu Xiuxiu, and to mask the faces of the selfie-takers with a standard Photoshop lens flare effect: "It's paradoxical," she muses, "because the whole point of taking a selfie is that you want other people to see it, it's an experience of sharing experience; but in my work, you do not see their faces, that's not the point" (Ying Miao, personal communication 2015). 


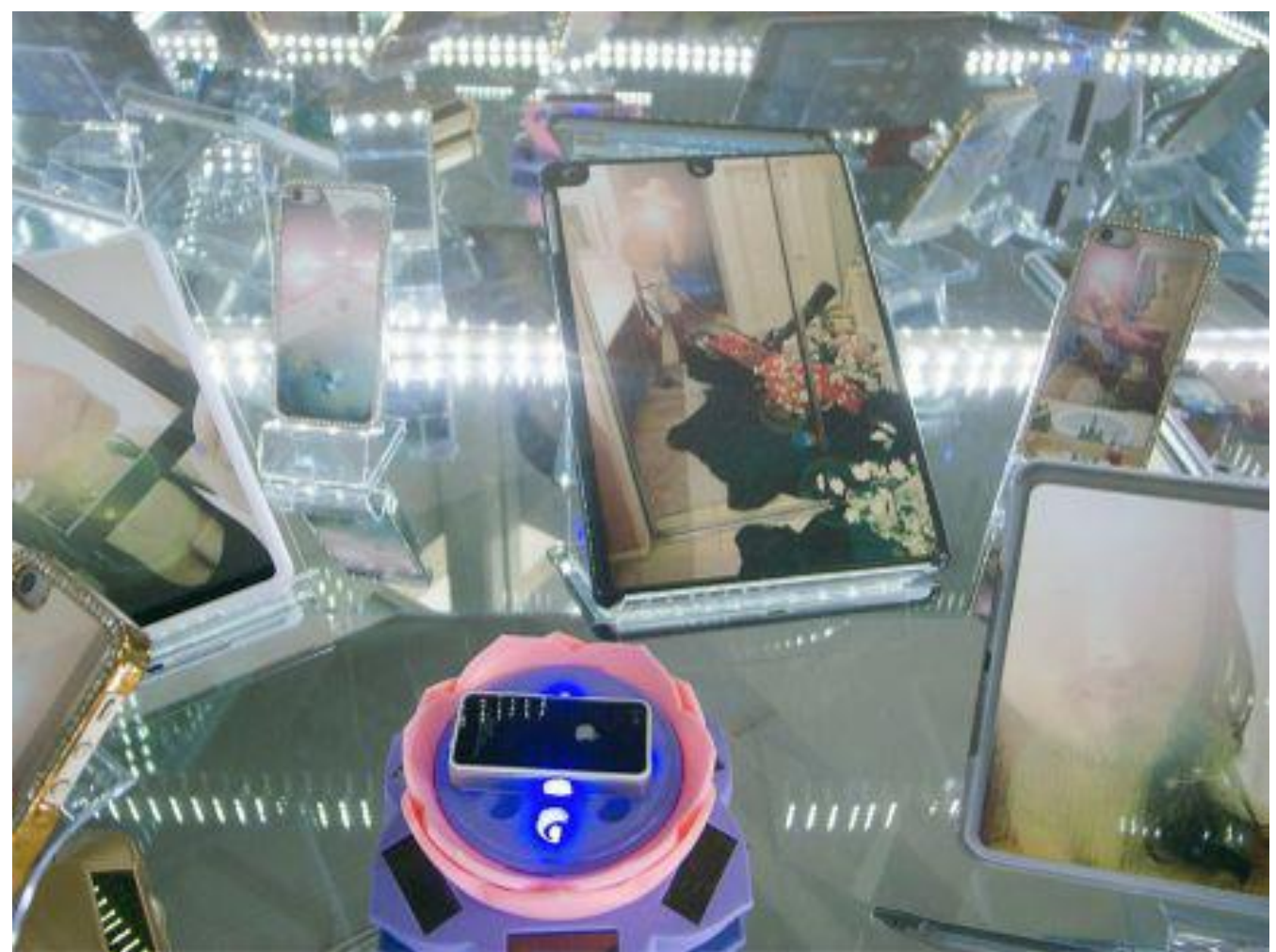

Figure 10. Detail of Ying Miao's mixed media installation \#mememe (V Art Centre, 2014).

All these contemporary art works and projects exemplify different possibilities of collecting, curating and presenting vernacular self-representation in different Chinese media ecologies: analog photography, personal media diaries, voyeuristic iPad selfies, volunteered nude photography, WeChat storytelling, personalized device cases. Yet, the list of our sources of inspiration would not be complete without a mention of Wang Lang and Liu Xinhua's Implemental Photography. Dedicated to the "ongoing and ultimately infinite task of cataloging photographic practice in late 20th century China" (Borysevicz 2007, 8), Wang and Liu unravel the visual constructions of modern Chinese visual culture by collecting, categorizing thematically and re-photographing portrait photography, propaganda materials, magazines and advertisement. In their photographs of photographs, gongju sheying ('implemental photography') is deployed as a strategy to evidence aesthetic constants against the material backdrop of photography itself. In times of ubiquitous imaging and networked digital devices, implemental photography becomes one of the many aesthetic devices of vernacular portraiture: Fig. 11 collects some examples of how users utilize mobile devices to take digital snapshots of old analog photographs. Wallis (2013) offers a vibrant insight into this practice among female migrant workers:

To counter such feelings of urban anomie, she used her phone as a sort of virtual sanctuary by storing images that gave her "peace of mind" (xinqing уиуие). [...] Perhaps never was this more profoundly evident that in something that I came across numerous times, and this was pictures of pictures that were stored on the phone. [...] in the pictures of pictures, aesthetics merged with aspirations, and again this reflected a transcendent immobile mobility afforded by the mobile phone. $(2013,135-138)$ 


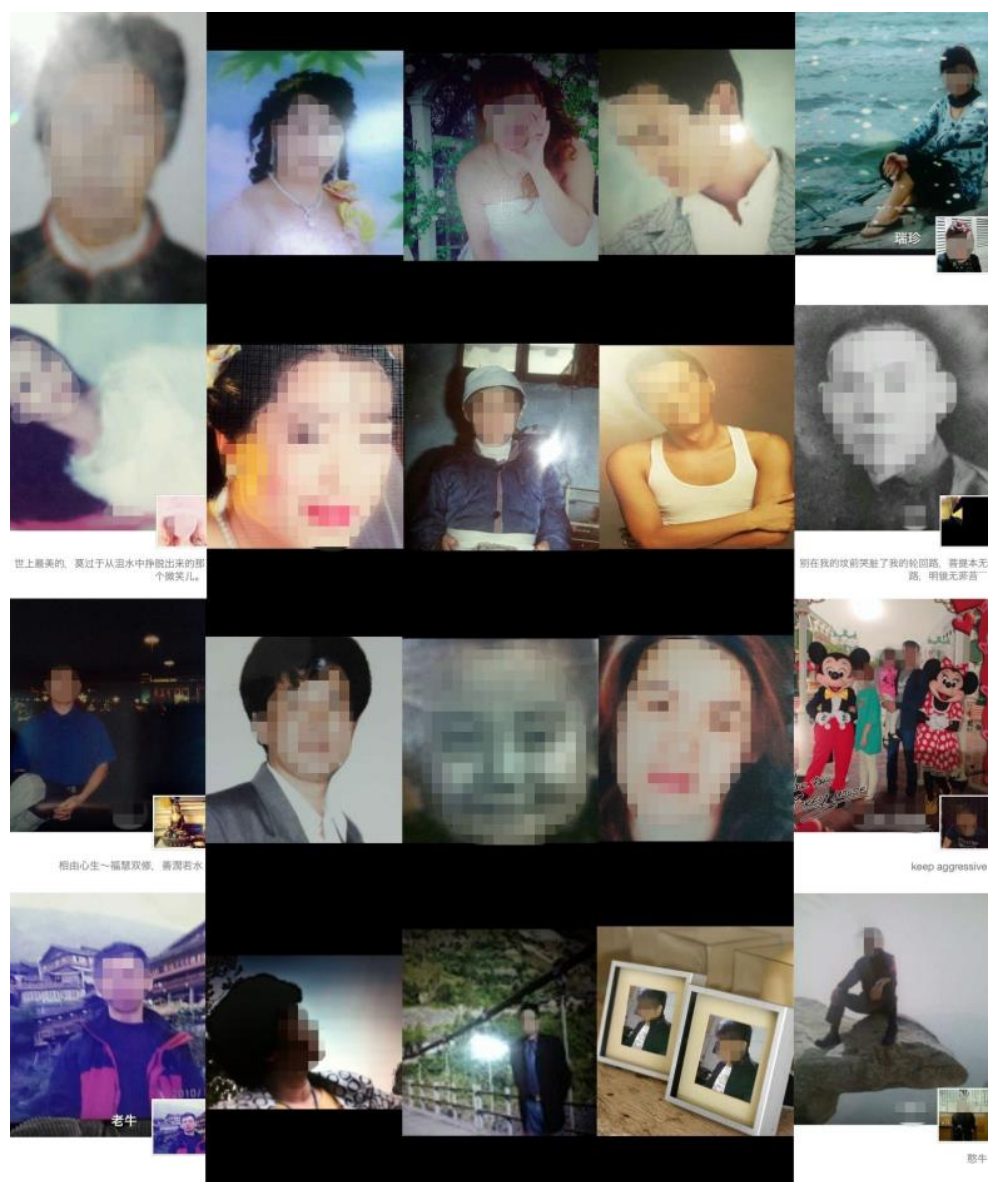

Figure 11. Vernacular implemental photography: Digital photographs of analog photographs used as WeChat profile pictures. From Proksell's collection of public WeChat selfies (collage, pixelated).

\section{Conclusion: The ways we worked}

Everyone with a cell phone, point and shoot camera; all the media, medical and security industries are ceaselessly producing images. Processing these images, much less deciphering their truthfulness or authenticity is a mind-boggling task. (Borysevicz 2007, 9)

We had thrown ourselves in the research process behind this essay naively hoping to find something about Chinese selfies. Perhaps, we thought, the aesthetics of zipai will emerge from the collection of a growing body of found profile pictures, and will be confirmed by interviews and discussions. Even better: poses, accessories and canons of self-fashioning could reveal linkages to the visual culture of Mao's China, filtered by the consumer revolution of the 1980s, and inflected by the images of advertising and media. Instead, the more pictures we collected, artists we interviewed, and people we discussed selfies with, the less comfortable we felt about making general claims regarding vernacular self-portraiture in China. What we had in our hands 
were pictures of people taking selfies, joking about selfies, editing their and their friends' selfies, making statements about their lives through selfies, selling things through selfies, and so on. At the same time, local artists were incorporating this vernacular genre of self-portraiture into their own practice, each from a different point of view. We were left with a paper to write and an artwork to put together.

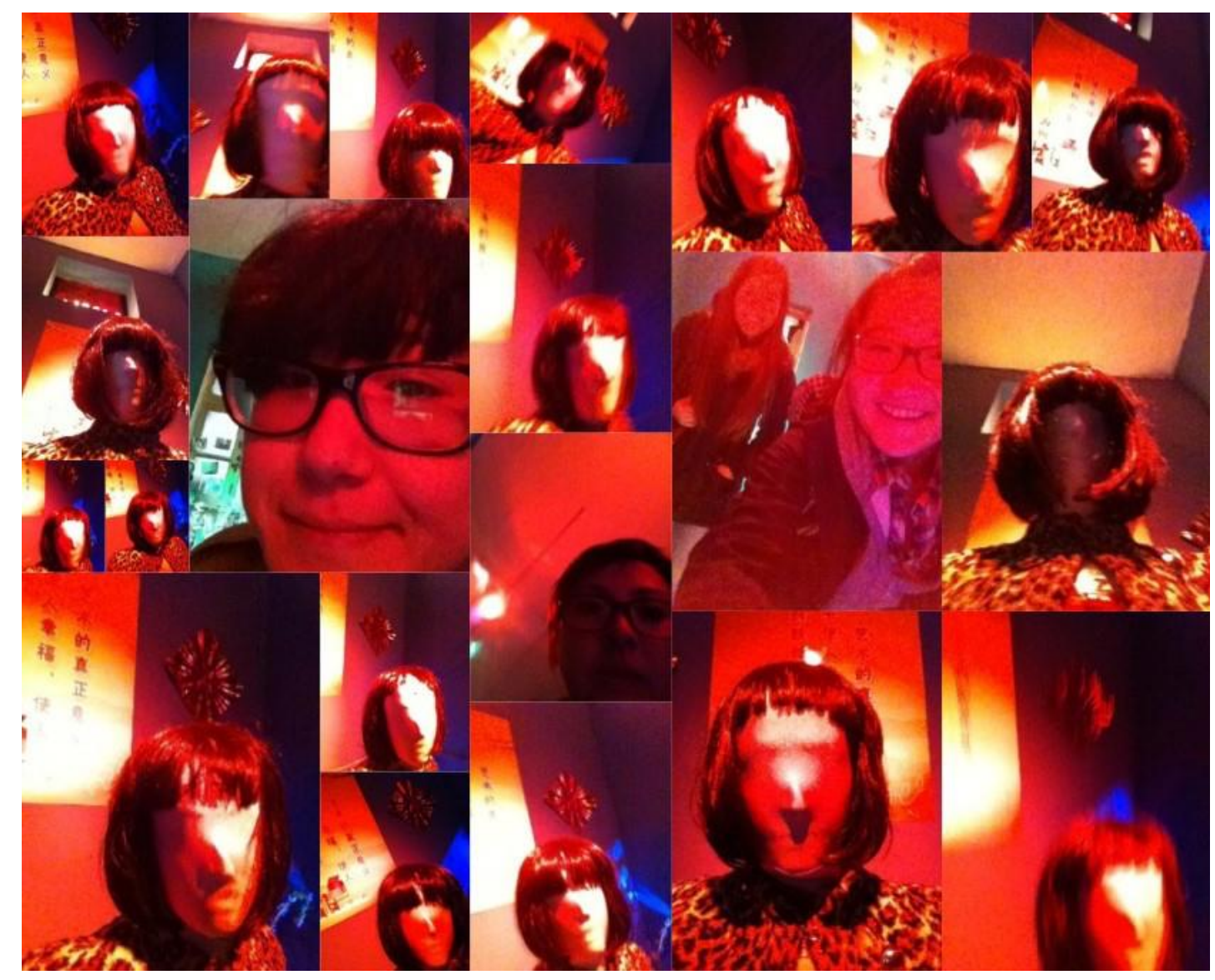

Figure 12. Selfies shot during the first performance of DongXi DongXi, Beijing.

On November $23^{\text {rd }}, 2014$, Michelle Proksell and Ophelia S. Chan debuted their performance piece DongXi DongXi at a contemporary art event in an abandoned hutong space in Beijing. The character of DongXi DongXi, played by Michelle, was part of a 'Living Shrine' installed in the last room of the housing unit, serving as the ending point of the exhibition. As the documentation of the event reports:

DongXi DongXi sat on a lifted platform in the front of the room illuminated by bug zappers, Christmas lights, projections, humidifiers, motivational posters looping on an iPad, in a set adorned with plastic flowers, glowing figures, crystals, broken glass and tree branches. In the left hand of DongXi DongXi was held a fresh piece of dragon fruit, in the right hand an iPod touch with the 
selfie mode turned on facing the audience who walked in - every so often DongXi DongXi turning the selfie on itself. Instead of a mirror, that this absurd "spiritual character" would have held in another day and age to represent how we see ourselves reflectively, DongXi DongXi turned the camera on the audience instead, giving them the ability to capture themselves in a kind of "spiritual awakening" in the most natural way possible to them - the selfie.

As Ophelia recalls,

the performance was actually very straightforward, DongXi DongXi seemed a bit like a statue, so some people in the audience would think it was just a sculpture. Most audiences kept a certain distance, some of them went to have some interaction with it, and a few of them even zipai with her iPod. I think this was the most interesting part. All in all, I think most of the setup was accessory, just the iPod was essential... Let's say it like this, this time the character really reminded me of Hello Kitty. Why do people like her so much? Besides her many designs, I think it's also because she doesn't have a mouth, she doesn't express emotions, that is to say, she can adapt to your emotions, she is the character you want her to be. So when you see a female body without facial features appear in this setting, it's really quite surreal, unexpected, but if you actually come close to her, you can form a spiritual connection with the cultural elements you find in the installation. (Ophelia S. Chan, personal communication 2014)

DongXi DongXi's faceless figure, sitting on an altar adorned with an array of everyday paraphernalia, LED lights and digital technologies, snapping selfies of itself and occasionally turning the gaze of its iPod on curious members of the audience (Fig. 12) incorporates many of the insights the authors gathered through the exploration of Chinese selfies as a vernacular genre of relational and locational self-portraiture. The installation on which it sits is decorated by a collection of objects from the material culture gleaned from the backgrounds of WeChat selfies. Its featureless face recalls the pixelated looks of anonymized found selfies from Michelle's collection. Its iPod, from powerful prosthetic for ethnographic research, becomes the interactive and productive gaze of the installation. This paper, in turn, couldn't have been written without the sustained involvement in creative practice, which also put both authors in touch with a wide range of visual art practitioners in China and abroad.

This ongoing engagement in processes of data collection, discussion, performance and writing illustrates how the ways of working of anthropologists and artist can interlock and inform one another in the making of representation itself - be it textual, visual or performative. As Schneider \& Wright (2013) put it, this means "approaching creativity and meaning as something often emergent, rather than prefigured or planned. Theory is now in the way of making, rather than outside it" $(2013,1)$. We started from a specific function of a Chinese mobile phone app, and we decided to focus on a genre of vernacular photography to explore "the visual publicization of ordinary life in a ubiquitous photoscape" (Hand 2012, 1). We traced the contours of the sociotechnical context of selfies on WeChat public profiles, attempted a negotiation with the unresolvable ethical quandaries of representing other people's self-representations, and shown 
how artists and photographers are confronting the same issues. Our hope is to have highlighted how visual artifacts, social technologies and creative practices interact in the media ecologies we traverse through our everyday lives, while also providing an account of how "ways of working are central to the sorts of creativity employed within projects, the kinds of collaborations involved, and the production of outcomes whether those are artworks or anthropological representations" (Schneider \& Wright 2013, 1). Albert Camus explained this in a much more poetic way:

For the same reason as the thinker, the artist commits himself and becomes himself in his work. That osmosis raises the most important of aesthetic problems. Moreover, to anyone who is convinced of the mind's singleness of purpose, nothing is more futile than these distinctions based on methods and objects. There are no frontiers between the disciplines that man sets himself for understanding and loving. They interlock and the same anxiety merges them. $(2005,94)$

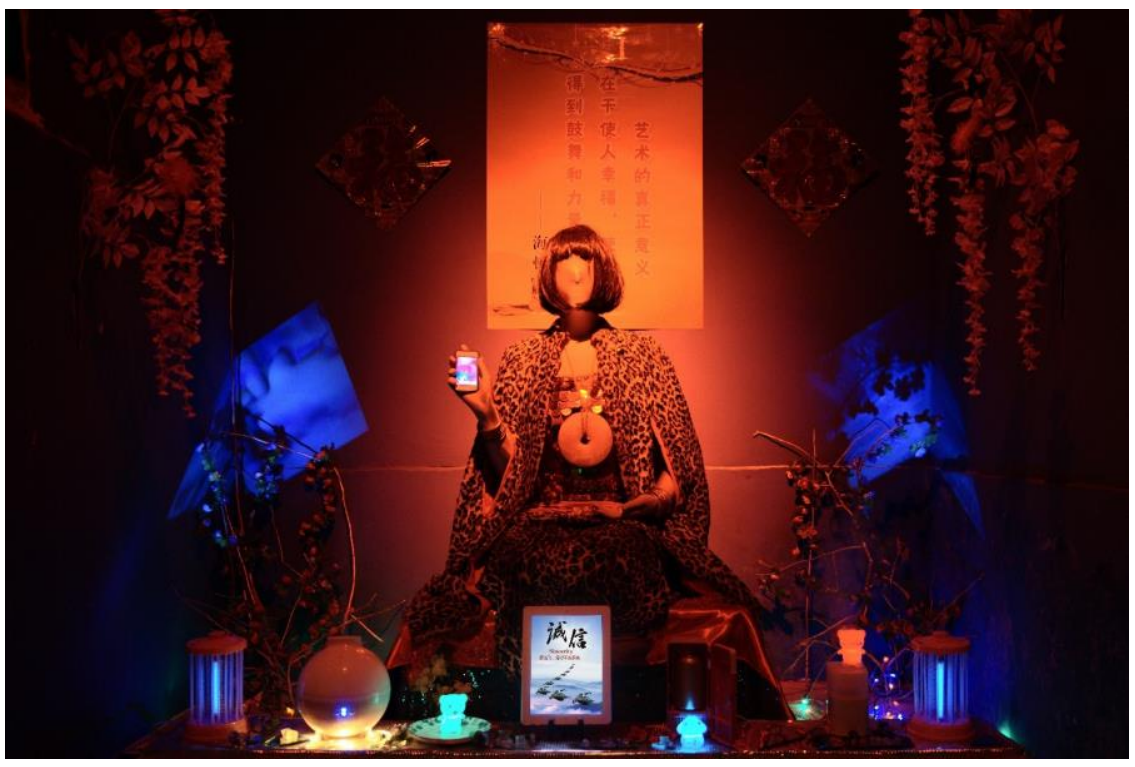

Figure 13. DongXi DongXi on its altar, Beijing.

\section{Acknowledgment}

The authors' gratitude goes to Thomas Sauvin (photo collector), Liu Zheng (photographer), James D. Poborsa (doctoral candidate, University of Toronto), Da Gua (artist), Michael Beets (transmedia artist), Ying Miao (artist), and all the anonymous and anonymized research participants for their willingness to share with us their experiences and expertise, and for providing us with the information and materials which made this essay possible. 


\section{References}

Allmark, P. (2011). Towards a photographie féminine: Photography of the city. In S. Spencer, Visual research methods in the social sciences: Awakening visions (pp. 171-183). London, United Kingdom: Routledge.

Berger, J. (1972). Ways of seeing. London, United Kingdom: Penguin.

Borysevicz, M. (2007). Mission accomplished. In L. Wang \& X. Liu, Implemental photography (pp. 8-9). Shanghai, China: DDM Warehouse.

Bourdieu, P. (1990). Photography: A middle-brow art. (S. Whiteside, Trans.). Cambridge, United Kingdom: Polity Press.

boyd, danah, \& Marwick, A. (2011). Social steganography: Privacy in networked publics.

Presented at the ICA, Boston, MA. Retrieved from http://www.danah.org/papers/2011/Steganography-ICAVersion.pdf

Bruckman, A. (2002). Studying the amateur artist: A perspective on disguising data collected in human subjects research on the Internet. Ethics and Information Technology, 4(3), 217231. http://doi.org/10.1023/A:1021316409277

Camus, A. (2005). The myth of Sisyphus. (J. O’Brien, Trans.) (15th ed.). London, United Kingdom: Penguin.

Clifford, J. (1986). Introduction: Partial truths. In J. Clifford \& G. E. Marcus (Eds.), Writing culture: The poetics and politics of ethnography (pp. 1-26). Berkeley, CA: University of California Press.

Critchley, S. (2002). On humour. London, United Kingdom: Routledge.

Croghan, R., Griffin, C., Hunter, J., \& Phoenix, A. (2008). Young people's constructions of self: Notes on the use and analysis of the photo-elicitation methods. International Journal of 
Social Research Methodology, 11(4), 345-356.

http://doi.org/10.1080/13645570701605707

Danova, T. (2014, May 16). WeChat, the number two mobile messaging app in the world, has almost 400 million users, but growth is slowing. Retrieved June 12, 2014, from http://www.businessinsider.com/wechat-nears-400-million-users-but-growth-is-slowing2014-5

Farrall, K., \& Herold, D. K. (2011). Identity vs. anonymity: Chinese netizens and questions of identifiability. In D. K. Herold \& P. Marolt (Eds.), Online society in China: Creating, celebrating, and instrumentalising the online carnival (pp. 165-183). Abingdon, United Kingdom: Routledge.

Fuller, M. (2005). Media ecologies: Materialist energies in art and technoculture. Cambridge, MA: MIT Press.

Goffman, E. (1990). The presentation of self in everyday life. London, United Kingdom: Penguin. Hand, M. (2012). Ubiquitous photography. Cambridge, United Kingdom: Polity Press.

Hein, W., O’Donohoe, S., \& Ryan, A. (2011). Mobile phones as an extension of the participant observer's self: Reflections on the emergent role of an emergent technology. Qualitative Market Research: An International Journal, 14(3), 258-273. http://doi.org/10.1108/13522751111137497

Hogan, B., \& Wellman, B. (2014). The relational self-portrait: Selfies meet social networks. In M. Graham \& W. H. Dutton (Eds.), Society and the Internet: How networks of information and communication are changing our lives (pp. 53-66). Oxford, United Kingdom: Oxford University Press.

Hölzl, I. (2009). Self-portrait/self-vision: The work of Samuel Fosso. Nka: Journal of Contemporary African Art, 24(1), 40-47. 
Huang, N. (2010). Locating family portraits: Everyday images from 1970s China. Positions: Asia Critique, 18(3), 671-693. http://doi.org/10.1215/10679847-2010-018

Hudson, J. M., \& Bruckman, A. (2004). "Go Away": Participant objections to being studied and the ethics of chatroom research. The Information Society, 20(2), 127-139. http://doi.org/10.1080/01972240490423030

Lancette, N. (2014, April 26). Is WeChat China's homegrown MobileOS? - Speculating on the future of WeChat. Retrieved June 12, 2014, from https://medium.com/technology-cultureproductivity/is-wechat-chinas-homegrown-mobileos-9fee8bca456b

Lee, S. Y. (2014, August 7). China tells South Korea it blocked KakaoTalk, Line to fight terrorism. Retrieved April 16, 2015, from http://www.reuters.com/article/2014/08/07/ussouthkorea-china-apps-idUSKBN0G709E20140807

Li, R. (2014). Zipai ['Selfie'] [MP3]. China: Warner Music.

Markham, A., \& Buchanan, E. (2012). Ethical decision-making and Internet research: Version 2.0 - Recommendations from the AoIR Ethics Working Committee. AoIR. Retrieved from http://www.aoir.org/reports/ethics2.pdf

McKay, T. (2014, March 28). A psychiatric study reveals selfies are far more dangerous than you think. Retrieved June 12, 2014, from http://www.policymic.com/articles/86287/apsychiatric-study-reveals-selfies-are-far-more-dangerous-than-you-think

Nash, V. (2014). The politics of children's Internet use. In M. Graham \& W. H. Dutton (Eds.), Society and the Internet: How networks of information and communication are changing our lives (pp. 67-80). Oxford, United Kingdom: Oxford University Press.

Nelson, K. (2014, August 3). Look: Ladies' “armpit hair selfies” take over Chinese web. Retrieved December 15, 2014, from http://shanghaiist.com/2014/08/03/armpit-hairselfies.php 
Oxford Dictionaries. (2013, November 19). Oxford Dictionaries Word of the Year 2013.

Retrieved from http://blog.oxforddictionaries.com/press-releases/oxford-dictionariesword-of-the-year-2013/

Poster, M. (2011). An introduction to Vilém Flusser's Into the Universe of Technical Images and Does Writing Have a Future? In V. Flusser, N. A. Roth (Trans.), Into the universe of technical images (pp. ix-xxvii). Minneapolis, MN: University of Minnesota Press.

Proksell, M. (2014). SHELLY_P_VS_MICHELLE. Retrieved June 12, 2014, from http://michelleproksell.com/www.michelleproksell.com/SHELLY_P_VS_MICHELLE.ht $\mathrm{ml}$

Punj, R. (2012, October). Visual Encyclopedia of the People's Republic - Liu Zheng’s monumental photo atlas The Chinese. Retrieved June 8, 2014, from http://dbartmag.com/en/72/feature/visual-encyclopedia-of-the-peoples-republic-liu-zhengsmonumenta/

Rettberg, J. W. (2014). Seeing ourselves through technology: How we use selfies, blogs and wearable devices to see and shape ourselves. Basingstoke: Palgrave Macmillan.

Ryan, E. G. (2013, November 21). Selfies aren’t empowering. They're a cry for help. Retrieved June 12, 2014, from http://jezebel.com/selfies-arent-empowering-theyre-a-cry-for-help1468965365

Saltz, J. (2014, January 27). Art at arm's length: A history of the selfie. Retrieved June 8, 2014, from http://www.vulture.com/2014/01/history-of-the-selfie.html

Sanderson, E. (2011, December 18). Out Is etc. Retrieved June 14, 2014, from http://www.artslant.com/cn/articles/show/29084

Schneider, A., \& Wright, C. (2013). Ways of working. In A. Schneider \& C. Wright (Eds.), Anthropology and art practice (pp. 1-24). London, United Kingdom: Bloomsbury. 
Sontag, S. (1977). On photography. London, United Kingdom: Penguin.

Spencer, S. (2011). Visual research methods in the social sciences: Awakening visions. London, United Kingdom: Routledge.

Tencent Inc. (2014, February 20). WeChat privacy policy. Retrieved May 21, 2015, from http://www.wechat.com/en/privacy_policy.html

Tifentale, A. (2014). The Selfie: Making sense of the "Masturbation of Self-Image" and the “Virtual Mini-Me.” Software Studies Initiative. Retrieved from http://d25rsf93iwlmgu.cloudfront.net/downloads/Tifentale_Alise_Selfiecity.pdf V Art Centre. (2014). Ying Miao - .GIF ISLAND. V Art Centre. Retrieved from http://www.vartcenter.com/uploads/1/1/9/4/11945410/giflisland.pdf

Vasey, G. (2013, November). Self2Selfie. Art Monthly, 371, 5-8.

Wallis, C. (2013). Technomobility in China: Young migrant women and mobile phones. New York, NY: New York University Press.

Wendt, B. (2014). The allure of the selfie: Instagram and the new self-portrait. Amsterdam, The Netherlands: Institute of Network Cultures.

Ye, Q. (2011). Shejiao wangzhan shang de ziwo zhanshi duibi yanjiu: Yi Juyouwang de zhongmei yonghu weili [A comparative study of self-presentation on social networking websites: Taking Chinese and American Juyouwang users as examples]. In B. Yang \& H. Xu (Eds.), Pingtai meili yu wutai youhuo: Zhongguo hulianwang chuangbo zhong de xingdongzhe [Platform glamour and stage lure: The actors in China's Internet communication] (pp. 125-146). Beijing, China: Zhongguo Shehuikexue Chubanshe.

Gabriele de Seta is a media anthropologist studying digital folklore and media practices of vernacular creativity in contemporary China. He collects, curates and narrates the genres of usergenerated content, local humor and platform-specific aesthetics circulating across Chinese 
postdigital media ecologies. His research work is chronicled on his website http://paranom.asia

Email: notsaved@live.com

Michelle Proksell, born in Saudi Arabia to expat American parents, is an independent researcher, curator, artist, musician, photographer and writer currently based in Beijing, China. Her work focuses on the emergence of digital, new media and Internet art in China. The majority of her archival and curatorial work is published on her online gallery http://netize.net

Email: michelleproksell@gmail.com 